Article

\title{
The Self-Action Leadership Model: A Qualitative, Nomological Expansion of Self-Leadership Theory Rooted in Action Research Theory
}

\author{
Jordan Jensen ${ }^{1, *}$, Christopher Neck ${ }^{2, *}$ and Rodney Beaulieu ${ }^{3, *}$ \\ 1 Freedom Focused, Conroe, TX, USA \\ 2 Management at Arizona State University, Tempe, AZ, USA \\ 3 Human Development Department, California State University San Marcos, San Marcos, CA, USA \\ * Correspondence: jordanjensen1@gmail.com; christopher.neck@asu.edu; rbeaulieu@csusm.edu
}

\begin{abstract}
In 2015, the Self-Action Leadership Theory - a qualitative, nomological expansion of selfleadership theory rooted in atmospheric and astronomical metaphor aimed at expanding the personal freedom of individuals, organizations, and nations by bolstering the existential growth of individuals through a series of Maslow-esque stages of holistic, personal development. This article introduces an accompanying, practitioner-based Model of Self-Action Leadership (SAL) aimed at the implicit enhancement of a holistic range of administrative processes through explicit training, mentoring, and coaching in the model's general and universally-applicable principles and practices. The SAL model produces an original construct of personal leadership practice that builds upon the extant self-leadership academic canon, which dates back to 1983 (Manz, 1983). It also provides an analogue to four of the five core processes of Project Management by positioning a self-action leader (an individual) as the ongoing "project" at hand. The SAL Model is rooted in action research and was developed through a variety of self-oriented, action research projects in conjunction with a comprehensive, qualitative, analytical autoethnographic study of a scholar's life experiences.
\end{abstract}

Key Words: Self-Action Leadership (SAL), SAL model, SAL theory, nomological, existential growth, organizational (or corporate) citizen, SAR project, SAL project, step-habit, Self-Declaration of Independence, Self-Constitution

Note: Self-Action Leadership will be capitalized throughout this paper as a visual means of further differentiating it from self-leadership-a similar construct.

\section{Introduction}

As an administrator, it does not really matter whether you are managing issues involving innovation and productivity (Jenkin, 2013), collaboration and cultural competence (Osula \& Ng, 2014), outsourcing (Sardar, Lee, \& Memon, 2016), global competition (Albors-Garrigos, de Miguel Molina, B., \& de Miguel Molina, M., 2014), human resource management (Lin, 2013), or something else, the fundamental efficacy of your overall results are going to be largely contingent on the character, competence, and capacity of your human capital. Thus it is that leadership and professional development (MacPhee, Chang, Havaei, \& Chou, 2014), in conjunction with recruiting and screening applicants in possession of strong personal character and integrity, are the most important components of any and every administrative function and purpose, and providing opportunities for professional development.

Thoreau (2001) famously wrote that, "There are a thousand hacking at the branches of evil to one who is striking at the root" (p. 62). "Evil" in this context, could be viewed as long-term organizational inefficacy (a failure to get results). This paper posits that administrators in general focus too much of their time, energy, and focus on the "branches" of organizational inefficacy- 
such as inadequate policies and procedures, flawed systems, insufficient capital and resources, short-cuts to results, etc. - while too often neglecting the single greatest asset they possess (their human capital) - whose competence and character development form the "roots" of their long-term success (or failure). This is not to say that policies, procedures, systems, capital, resources, technology, etc., are not important; they certainly are. It is simply to suggest that they are secondary to other, more primal and vital fundamentals, and that the acquisition, development, and retention of human capital (the people) should always be viewed as both pre-requisite and preeminent to any secondary or tertiary considerations involving policies, processes, capital, and natural resources (the things).

It also suggests that while personal and professional development is ultimately the responsibility of each individual (highlighting the need to develop self-leadership and an internal locus of control [Neck, Manz, \& Houghton, 2017, p. 157-158] among all agents in an organization), that leaders, managers, and administrators (i.e. SuperLeaders, Manz \& Sims, Jr., 2001) are likewise responsible for providing adequate mentoring, training, and coaching opportunities rooted in sound theory and practical models of application. With this assumption in mind, the question naturally arises: if we are to teach, coach, and mentor our people more effectively, what exactly should we be teaching-and how often? Our proposed solution to this question rests in the SelfAction Leadership (SAL) model introduced in this paper, as well as its accompanying theory and philosophy introduced last year.

The purpose of the SAL model is to provide administrators and their colleagues and subordinates with a guide for thinking, speaking, and doing that leads to Existential Growth (a SAL theory reference to holistic personal growth), personal freedom (both personally and professionally), collective liberty, and organizational efficacy through the influence of the individual. It was created in an effort to empower individuals to identify, account for, and then address personal and professional problems utilizing an inside-out (Self-Action Leadership) approach. It was designed to combat cultures of irresponsibility, victimization, and mediocrity that exist to varying degrees within the minds and hearts of individuals and the ranks of organizations and populations everywhere.

\section{Discussion}

In his famous speech at the Sorbonne in Paris, France, on April 23, 1910, ex-President of the United States-Theodore Roosevelt-made a cogent appeal to the import of the average citizen in a republic.

"Under forms of other government, under the rule of one [person] or very few [people], the quality of the leaders is all-important. ... But with you and us the case is different. ... For you and us the question of the quality of the individual citizen is supreme. ... In the long run, success or failure will be conditioned upon the way in which the average man, the average woman, does his or her duty, first in the ordinary, every-day affairs of life, and next in those great occasional cries which call for heroic virtues. The average citizen must be a good citizen if our republics are to succeed. The stream will not permanently rise higher than the main source; and the main source of national power and greatness is found in the average citizenship of the nation. Therefore it behooves us to do our best to see that the standard of the average citizen is kept high."

A clear, corporate analogue to this reference is easily drawn by comparing citizens and their republic to self-leaders and their organization, especially when organizations are (or are aiming to become) self-directed (Stokes, 1994) or self-managed (Manz \& Sims, Jr., 1987) work teams. Thus we may refer to the organizational or "corporate citizen" (Burchell \& Cook, 2006; Saiia \& Cyphert, 2003; \& Caroll, 1998; 1991).

In nineteenth and twentieth-century corporations, individual workers were often valued little more than the financial capital, raw materials, and machinery they managed, processed, or 
operated. These traditional corporate hierarchies have gradually evolved into increasingly flattened hierarchies managed by less-involved, collegial SuperLeaders (Manz \& Sims, Jr., 2001) who facilitate the work of self-directed work teams in a less obtrusive manner, granting greater autonomy to individual workers throughout the delegation process. This evolution has dramatically increased the perceived value of the individual organizational "citizen." Concurrently, the responsibility of every agent in an organization to discover and develop one's individual voice (Covey, 2004) has grown considerably. Individual workers can no longer expect to be spoon-fed every bit of necessary information they may need, nor can they expect managers to metaphorically "hold one's hand" at each step throughout the process. While workers should expect frequent communications from the leadership, such as updates on progress and strategic plans for improving operations, they must also bear the responsibility of contributing to the organizational goals, plus commit to ongoing professional development.

Later in his speech, Roosevelt addressed the critical role that education must play in the development of good citizenship, a fundamental assumption in community and participatory action research.

"Let those who have, keep, let those who have not, strive to attain, a high standard of cultivation and scholarship. Yet let us remember that these stand second to certain other things. There is need of a sound body, and even more of a sound mind. But above mind and body stands character - the sum of those qualities which we mean when we speak of a man's force and courage, of his good faith and sense of honor. ... I believe, of course, in giving to all people a good education. But the education must contain much besides booklearning in order to be really good. We must ever remember that no keenness and subtleness of intellect, no polish, no cleverness, in any way make up for the lack of the great solid qualities. Self-restraint, self mastery, common sense, the power of accepting individual responsibility and yet of acting in conjunction with others, courage and resolution - these are the qualities which mark a masterful people. Without them no people can control itself, or save itself from being controlled by the outside. ... I pay all homage to intellect and to elaborate and specialized training of the intellect; and yet ... more important still are the commonplace, every-day qualities and virtues."

Just as citizens in a republic must become well educated-and especially in regards to character and "the great solid qualities," if republics are going to succeed and thrive in the longrun, workers in an organization must do likewise if organizational efficacy is to be maximized and longevity ensured. The purpose, therefore, of the SAL philosophy, theory, and now its accompanying model, is to provide an explicit, albeit purposely general, road map for the personal and professional development and training of individual corporate "citizen" workers who efficiently and effectively play their role in ways that contribute to the maximization of said organizational efficacy and longevity.

In the words of Millet (2000), "Some things simply matter more than others" (p. ix). We suggest that this is the case with both the administrative sciences and with whatever personal and professional training may undergird and support them. Goethe famously stated that, "things which matter most must never be at the mercy of things which matter least." In the spirit of Goethe's wisdom, we suggest that the two (2) most important variables in the long-term success of any venture involve:

1). The quality of each individual hired.

2). The quantity and quality of subsequent training, coaching, mentoring, and leadership.

The process of hiring quality individuals is beyond the scope of this paper. Our focus is to introduce a template for quality training, mentoring, and coaching that follows the hiring process. This template is referred to as the Self-Action Leadership-or SAL-model, and is introduced herein. The time has come to begin to invest more academic and corporate capital on "things which matter most." 
The SAL model was inspired in part by a wide range of historical wisdom literature, including poetry. According to Gioia (2002), "a poem can condense immense amounts of intellectual, sensual, and emotional meaning into a single line or phrase" (p. 221). In 1846, Henry Wadsworth Longfellow-once viewed "as the most distinguished poet America had produced" (Gioia, 2004, p. 54)-unwittingly penned a few eloquent stanzas of verse that would, 150 years later, inspire the academic explication presented in this work. Because of this influence, and subject relevance, the authors of this paper deem it appropriate to reproduce this poem in its entirety as a preface to formally introducing the SAL model.

\section{THE BUILDERS ${ }^{1}$}

ALL are architects of Fate,

Working in these walls of Time;

Some with massive deeds and great,

Some with ornaments of rhyme.

Nothing useless is, or low;

Each thing in its place is best;

And what seems but idle show

Strengthens and supports the rest.

For the structure that we raise,

Time is with materials filled;

Our to-days and yesterdays

Are the blocks with which we build.

Truly shape and fashion these;

Leave no yawning gaps between;

Think not, because no man sees,

Such things will remain unseen.

In the elder days of Art,

Builders wrought with greatest care

Each minute and unseen part;

For the Gods see everywhere.

Let us do our work as well,

Both the unseen and the seen;

Make the house, where Gods may dwell,

Beautiful, entire, and clean.

Else our lives are incomplete,

Standing in these walls of Time,

Broken stairways, where the feet

Stumble as they seek to climb.

Build to-day, then, strong and sure,

With a firm and ample base;

And ascending and secure

Shall to-morrow find its place.

${ }^{1}$ Longfellow, H.W. The Day is Done, reprinted from The Poetical Works of Longfellow (1912). Henry Frowde, Oxford University Press. Page 186. 
Thus alone can we attain

To those turrets, where the eye

Sees the world as one vast plain,

And one boundless reach of sky.

Assuming that humans are-at least in part_-"architects of [their own] fate," who were ever born who did not ponder and pontificate (at least a little bit) upon one's purpose and possibilities amidst the "boundless reach of sky" of one's own existence? Has a man or woman ever lived who has not spent time considering the kind of "structure [he/she might] raise" and "the blocks with which [he/she might] build"? Finally, has a human being ever drawn breath who intentionally aspired to "stumble" upon "broken stairways" in hopes only of descending into a downward spiral leading to an incomplete life? Drawing on this premise-that no one purposely falters or fails in life or one's career, nor does any man or woman ever intentionally "begin with" mediocrity, ignominy, or penury as an explicit "end in mind" (Covey, 1989, p. 95) - we hereby introduce the Self-Action Leadership model as a general roadmap that administrators and their subordinates (all of us as self-leaders \& life managers) can utilize to "Build to-day, then, strong and sure, With a firm and ample base" in the confident hope that ascendance and security can be ours so that "to-morrow [can indeed] find its place" for each one of us.

Review of the Self-Action Leadership Theory

A theory of self-leadership (Manz, 1983), called Self-Action Leadership (SAL), was recently introduced. This qualitative, nomological theory rooted in atmospheric and astronomical metaphor has an accompanying model-the Self-Action Leadership model. The SAL theory provides a philosophical and theoretical backdrop in support of the SAL Model. This SAL theory postures Self-Action Leadership as a theoretical analogue to self-leadership theory, albeit possessing a unique framework that explicitly mandates a moral imperative that differentiates a self-leader (any human being) from a self-action leader (someone who consciously and intentionally engages in patterns of thought, speech, and actions that lead to the long-term growth and constructiveness of self and/or others while avoiding contrasting patterns that lead to atrophy and destructiveness to self and/or others).

The SAL theory compares a self-action leader to a rocket ship traveling from ground zero through the various layers of Earth's atmosphere into deep Outer Space. Ground zero, each atmospheric layer, and deep Outer Space serve as nine metaphorical analogues to nine different Maslow-esque levels of existential growth attainable to self-action leaders.

\section{What is Self-Action Leadership?}

Self-Action Leadership, or just SAL for short, is a derivative of self-leadership theory (Manz, 1986). It consists of a comprehensive philosophy, theory and model (introduced herein). Self-Action Leadership is defined as: "Morally informed self-leadership that is action-oriented, focused on long-term results, and aimed at a continual rise in the Existential Growth of self and others" (p. 15). Self-leadership - as a field independent of Self-Action Leadership-will be covered in a later section. For the time being, let's define it simply as: "The art and science of leading oneself to achieved targeted objectives." Existential growth is defined as: The holistic (spiritual, physical, mental, emotional, social, moral, and financial) growth of personal character, capacity, and integrity." Note: The financial component has been added since the publication of the SAL theory to make seven, rather than six, key components of existential growth. This is the first publication that contains this additional component.

While analogous to self-leadership in many ways, Self-Action Leadership diverges from self-leadership by providing a comprehensive theory and model unique from Neck, Manz, and Houghton's (2017) Comprehensive Self-Leadership Framework (p. 181). It also differentiates itself by 
mandating a moral imperative that generally defines "Right" and "Wrong" thoughts, speech, and actions as follows:

Right: Thoughts, speech, and actions that create positive and constructive long-term consequences for self and others.

Wrong: Thoughts, speech, and actions that create negative and destructive long-term consequences for self and others.

\section{SAL Philosophy: The Problem \& Need}

Why construct and introduce the Self-Action Leadership theory and model? What are their practical and functional purposes? Schumacher (1977) sheds light on the answer to this question:

"Instruction on cultivating self-knowledge ... has been almost entirely lacking in the West for the last hundred years. That is why we cannot trust one another, why most people live in a state of continuous anxiety, why despite all our technologies communication becomes ever more difficult, and why we need ever more organized welfare to plaster over the gaping holes torn by the progressive disappearance of spontaneous social cohesion" ( $p$. 133-134).

Our repeated attempts in the Occident to fix deep, nagging, and lingering familial, organizational, national, and even global problems from the outside-in has dramatically failed. As history, literature, and even science amply evince, authentic, lasting change can only truly occur from the inside-out. Simply stated, micro changes must precede macro improvements. For the world to change, nations must change. For nations to improve, organizations (including families and individual relationships) must be transformed. For organizations to be transformed, individuals must strive for personal improvement. It all begins with the ONE-with YOU and with ME.

\section{Academic Roots of the Self-Action Leadership (SAL) Model}

The Self-Action Leadership model derives its academic fundamentals from self-leadership theory (Manz, 1986; 1992a) and action research (Beaulieu, 2013).

\section{Self-Leadership}

Self-leadership theory (Manz, 1986) is derived from social cognitive theory, intrinsic motivation theory, cognitive evaluation theory, motivation theory, leadership theory (Neck \& Manz, 2010, p. 4-5), and self-determination theory (Neck, Manz, \& Houghton, 2017, p. 8). SelfLeadership theory is conceptualized in Neck, Manz, and Houghton's (2017) Comprehensive SelfLeadership Framework (p. 181), and forms the basis of the scholarly field of self-leadership, which dates back to the early 1980s (Manz, 1983; Manz \& Sims, 1980).

"Self-leadership ... is a process through which individuals control their own behavior, influencing and leading themselves through the use of specific sets of behavioral and cognitive strategies" (Neck \& Houghton, 2006, p. 270). The academe's initial reception of self-leadership as an independent framework and subject of inquiry was tepid. Over time, however, it warmed due to increasing scholarly coverage (Neck \& Houghton, 2006), expansion (Manz \& Sims, Jr., 2001), (Houghton \& Neck, 2002), (Houghton and Yoho, 2005), (DiLiello \& Houghton, 2006), and diversification (Alves, Lovelace, Manz \& Matsypura, Toyasaki, and Ke, 2006), (Georgianna, 2007) (Pattni \& Soutar, 2009). Stewart, Courtright, and Manz's (2011) 30-year multilevel review in the Journal of Management evinced the field's burgeoning posture amidst related topics of inquiry. Clawson's (2008) humble scholarly admission further illuminates the academe's growing accession, not to mention the practical utility, of self-leadership oriented scholarship and training: 
"I remember when Manz (1983) first came out with his work on self-leadership. At the time it seemed odd to me. I will admit I am a slow learner on some things. I have come to believe that one of the biggest leadership issues is the inability of people - even and especially managers and executives - to lead themselves [effectively]" (p. 175).

Self-Action Leadership is substantively analogous to self-leadership in the sense that both deal specifically and extensively with the intentional direction and management of the self. The primary difference between the two lies in the uniqueness of their respective theories and models (frameworks) and the added moral imperative of SAL. It should be noted, however, that the SAL Model retains five specific components of Neck, Manz, and Houghton's (2017) Comprehensive SelfLeadership Framework (i.e. self-rewards, natural rewards, world altering strategies, self-observation, and self-analysis).

\section{Action Research}

What exactly is action research, or AR? Mumford (2001) has called AR a "vague concept" that "has been defined as research that involves practical problem solving which has theoretical relevance" (p. 12). Some see it as a more clear-cut concept, yet they define it with a similar complexity. For example, according to Cunningham (2008), action research "is a value-driven, cyclical, and transformative process that uses intervention in a setting, based on observation and theoretical constructs, to alleviate an observed problem or to increase the effectiveness of a practice in the setting" (p. 1).

Others prefer clearer, more concise definitions and explanations. For example, McKay and Marshall (2001) propose that, "the very essence of AR is encapsulated within its name: it represents a juxtaposition of action and research, or in other words, of practice and theory" (p. 46). French (2009) adds that, "the AR process starts with a notion in the practitioner's mind that a change is practice is justified" (p. 187).

Beaulieu (2013) argues, "there are many variations in action research, and it [therefore] resists simplistic definition" (p. 34). Yet there is a unifying thread of purpose running through virtually all AR initiatives.

"Although the body of literature about action research continues to grow and become more differentiated in its viewpoints and specializations, we can still find a common definition: action research is about improving the quality of human life, acquiring knowledge to become better practitioners, and developing strategies to address problems" (p. 33).

Beaulieu (2013) further asserts that there are "various ways action research is defined and applied" (p. 29). For example, it can be "accomplished through a collaborative process ... [or] done alone as an independent process" (p. 29). Because SAL-like S-L-is rooted in an independent, selfapproach to action and influence, it follows that SAL-oriented AR would utilize the latter, independent approach. Thus Self-Action Research-or SAR-was born, and is defined as follows: Action Research applied by, to, and for the self to gain self-awareness, aid self-improvement, and solve personal problems. SAR has since become the engine driving both the design and implementation of the SAL model as elucidated below.

SAR and SAL projects are the practical engines of Self-Action Leadership application. SAR projects are defined as: self-led action research initiatives aimed at increasing self-awareness, aiding self-improvement, and solving personal projects. SAL projects are defined as: Self-Action Leadership initiatives aimed at achieving targeted objectives that bolster the existential growth of self and others. For self-action leaders, SAR projects and SAL projects are conceptually indistinct, the end goal always being to do what is right in the accession of existential growth.

In consideration of all that has been written on the topic of action research, it became evident early on that various brands of AR had been unknowingly utilized in conducting most of the experiential research undergirding the SAL model. Furthermore, over time it became equally 
apparent that one AR model in particular-Kuhne \& Quigley's (1997) basic, cyclical model-would be a good template upon which the SAL model itself could be modeled. This particular model of AR identified "Four Core Processes of Action Research" (p. 25) as follows:

Process 1: Planning (Deciding how to deal with a problem)

Process 2: Acting (Implementing your plan)

Process 3: Observing (Paying attention and recording what is happening)

Process 4: Reflecting (Analyzing outcomes and revising plans for another cycle of acting) (p. 25)

Kuhne and Quigley (1997) position these four core processes as a cycle, with continual revolutions engaged as needed to achieve a targeted goal or objective. They then identify six specific steps to take as a part of three general phases contained within the four core processes ( $p$. 26-32). Additionally, 10 different data-gathering techniques are provided for us throughout the research process.

The SAL model uses this basic structure to identify FOUR (4) primary stages and twentyone (21) secondary steps to engage in successful SAL practice that leads to existential growth. Like Kuhne and Quigley's (1997) "Four Core Processes" (p. 25) and "Six Steps" (p. 26), the SAL model's four stages and 21 steps are arranged cyclically. A key philosophical difference lies in the fact that Kuhne and Quigley's cycle can be terminated upon the realization of a given objective or by satisfactorily solving a certain problem. On the other hand, the SAL model's process is designed to continue cycling indefinitely, recognizing that the ultimate goal-holistic SAL perfection-is not attainable in this life. The core of this paper will introduce these four core stages and their accompanying 21 action steps.

In conclusion, it was determined that a self-leadership model that is inherently "actionoriented" would be well served by the use of action research theory and practice in both its creation and design. Hence, AR - and now SAR - is a critical component of SAL.

\section{Research Method}

The SAL Model was constructed using a comprehensive (1,149 page), qualitative (Denzin \& Lincoln, 2011), analytic autoethnographic (Anderson, 2006) research study of a scholar's holistic life experiences. The academic apology for such a study lies in Furtner, Rauthman, and Sachse's (2011) suggestion that, "Self-leadership should be integrated within a nomological network" (p. 369) rather than a scientific or empirical framework. For reasons set forth in the explication of the SAL theory, the authors of this paper agree that the SAL model should likewise be nomologically, rather than scientifically or empirically, integrated. The Self-Action Leadership philosophy, theory, and model are thus nomological in both their construction and presentation.

Further academic apologies for this nomological construction and presentation lie in Schumacher's (1977) claim that, "Life is bigger than logic" (p. 123) and Roubiczek's (1964) existentialist view that "reason has limitations (p. 4) ... [and] that a purely logical, rational, scientific way of thinking illuminates only a strictly limited sector of reality" (p. 1). Moreover, such a rationality has limited powers and "is influenced by [our imperfect] human nature ... [and therefore] cannot and must not be considered as absolute" (p. 1).

"We rarely pay enough attention to the deeper meaning of our personal experience and of our feelings; we disregard inner knowledge. ... Philosophy, therefore, should start from one's own experience, one's own inner knowledge, and it is inner knowledge which should be qualified, enlarged, and in this way enriched. One's own experience must be admitted as evidence. Reason ... can serve this approach ... but it must never dictate" (p. 10-11, 12).

Roubiczek (1964) goes on to point out that: 
"There is meaning in many of our experiences, of nature and of human nature, in works of art, in books of literature or wisdom or religion; thus the urge to find meaning is so strong that it is part of our make-up, an undeniable experience. Once more we have to conclude that reason is not absolute, but limited ... and that we should find a way of thinking which could help us to deal with [life's] hauntingly real experiences. ... In short, reason must not dominate, but serve" (p. 6-7).

Thus it is that the author has drawn liberally from both personal experience and wisdom literature in constructing the SAL Model-an admittedly nomological construct that is only metaphorically scientific. As for our use of quasi-academic wisdom literature in support of the SAL Model, Schumacher (1977) offers a cogent apology for the use of such in this present endeavor when he wrote:

"All traditional wisdom, of which both Dante and Shakespeare are outstanding representatives, transcends ordinary, calculating logic and defines "The Good" as that which helps us to become truly human by developing our higher faculties - which are conditional on, and also part of, self-awareness" (p. 131).

Note: Self-awareness is the cognitive starting point of both S-L and SAL.

\section{Results: The Self-Action Leadership Model}

George Washington Doane was born the same year that his namesake-the George Washington-died. An educator and Bishop in the Episcopal Church, Doane was a contemporary of Longfellow, Emerson, Whittier, and other famous nineteenth century American poets. Doane's own best-known effort at verse reads thusly:

\section{LIFE SCULPTURE}

Chisel in hand stood a sculptor boy

With his marble block before him,

And his eyes lit up with a smile of joy,

As an angel-dream passed o'er him.

He carved the dream on that shapeless stone,

With many a sharp incision;

With heaven's own light the sculpture shone,-

$\mathrm{He}^{\prime} \mathrm{d}$ caught that angel-vision.

Children of life are we, as we stand

With our lives uncarved before us,

Waiting the hour when, at God's command,

Our life-dream shall pass o'er us.

If we carve it then on the yielding stone,

With many a sharp incision,

Its heavenly beauty shall be our own,-

Our lives, that angel-vision (Doane, 1920, p. 136).

In addition to Longfellow's The Builders, this poem of Doane's captures the essence of the inspiration behind the conception and development of the SAL model. While the model explicitly compares a self-action leader to the construction of a modern skyscraper rather than the sculpting of a statue out of clay, bronze, or other material, both images are apt metaphors that can be 
concurrently applied. Regardless which metaphor you employ, the goal of the SAL model is to provide self-action leaders with a concrete set of tools whereby they can successfully capture their individual "life-dream[s]" and then transfer their visions to real achievements that carry "heavenly beauty," whatever that may mean for each individual.

Fully fleshing out all particulars of the SAL model is beyond the scope of this paper. The goal of this paper is primarily to position the model within a framework of previously established academic schools and tools and introduce the research methods employed in its construction. A brief review of the models particulars, however, is presented below.

\section{Four Stages of Self-Action Leadership}

As mentioned earlier, the four primary stages of the SAL model are analogues to the "Four Core Process of Action Research" (Kuhne \& Quigley, 1997, p. 25).

The FOUR (4) primary stages of Self-Action Leadership are:

Stage 1: Planning \& Preparation (Drawing up Blueprints for Success)

Stage 2: Developing an Integrity Based Character (Building An Integrity-Based Foundation Rooted in Universal Laws)

Stage 3: Taking Action

Stage 4: Observation, Analysis, \& Change

These four stages of SAL are analogues to the FOUR (4) primary stages of constructing a skyscraper, as follows:

Stage 1: Pre-Construction

Stage 2: Building the Foundation

Stage 3: Constructing the Superstructure

Stage 4: Maintenance and Upgrades

\section{Stage 1: Drawing up Blueprints for Success}

Also known as the Planning \& Preparation Stage, the first stage of the SAL model involves seven steps-or habits. Habits may in fact be a better term than steps in the sense that each step is more of a characteristic to be developed than a task to be completed once and then disregarded. Since there theoretically is no ceiling to a human being's potential for existential growth, there is likewise no end to the cyclical application of the four stages and 21 steps; they are designed to be continually cultivated-as habits would be-throughout one's life. Despite this fact, a certain chronological process intentionally exists in the ordering of the habits; thus, these 21 habits maintain a semblance of "steps." To capture the dual nature of these unique 21 action items, we heretofore invoke the hybrid term, step-habits, in describing them. The seven (7) step-habits of stage one are:

1. Self-education

2. Relationship building

3. Self-awareness

4. Self-organization

5. Self-recording (journal keeping)

6. Self-oneness (the science and art of harmonizing the seven key components of your existence $\sim$ spiritual, physical, mental, emotional, social, moral, and financial

7. Self-constitution, including a Self-Declaration of Independence

These seven (7) SAL step-habits are direct analogues to seven (7) specific construction steps involved in the pre-construction process of building a skyscraper. These seven steps are: 
1. Gathering information

2. Consultation

3. Acquiring and allotting financial resources

4. Obtaining approvals and permits

5. Planning and scheduling

6. Assembling a cohesive team and crew

7. Drafting architectural/engineering blueprints

The first six step-habits are fairly descriptive making further explication beyond the scope of this paper. The seventh and last step-habit consists of drafting comprehensive personal and professional "Blueprints for Success" in the form of a Self-Declaration of Independence (S-DoI) and a Self-Constitution (S-C). The purpose of the former document-which is conceptually related to the United States' 1776 Declaration of Independence-is to identify internal and external forces holding one back from achieving one's fullest potential as a self-action leader, and then formally and intentionally "declaring one's independence" there from in an effort to psychologically prepare to design and live according to one's subsequently drafted Self-Constitution.

A Self-Constitution-which is conceptually related to the United States' 1787 Constitution-is a comprehensive SAL document that includes statements of personal vision, mission, values, goals, standards, mentors, etc. It is designed to act as a literal blueprint for your life in the same way an architectural blueprint serves as a plan of action in a construction project.

\section{Stage 2: Building An Integrity-Based Foundation Rooted in Universal Laws}

Also known as Developing an Integrity-Based Character, stage two involves developing the character and integrity required to obtain any long-term achievement that perpetuates a positive, lasting legacy. Like any vertical structure, a skyscraper must have a firm foundation if it is to successfully bear the weight of its superstructure.

A certain irony exists in the construction of a skyscraper's foundation. This irony is found in the fact that it can sometimes take as long (or longer) to construct a skyscraper's foundation (the part of the building that will eventually be hidden from sight) than it does to construct its superstructure (the part that everyone will eventually see-despite the fact that its superstructure is often much taller and requires far more material to build. A prime example of this reality is America's most famous new skyscraper-One World Trade Center, informally known as The Freedom Tower-a recently completed (2013-14) office building in Lower Manhanttan. This skyscraper is currently the tallest building in the United States and the entire Western Hemisphere. Excavating the foundation site and then building the foundation for this leviathan of a structure took approximately FOUR (4) years to complete. By comparison, the building's towering (1,776 foot, 104-story) superstructure took only approximately three (3) years to complete, and at the height of its construction, builders were raising a new floor every week!

The amount of time and effort required to plan and then build a structure's foundation underscores just how important this portion of the construction process is. It has been said that, "Character is forged by what you do when no one else is looking." Such it is with the construction of a building's foundation; its integrity is also forged underground-beyond the purview of virtually all who will eventually enter, work, or otherwise use the building in the future.

There are five step-habits introduced in Stage 2 of the SAL Model, as follows:

1. Honesty

2. Humility

3. Reverence

4. Rectification

5. Service 
These five SAL step-habits are direct analogues to five construction steps involved in building a skyscraper's foundation. These five steps are:

1. Conducting geological surveys

2. Drilling down to bedrock

3. Anchoring concrete/steel piles to bedrock

4. Pouring a steel-reinforced concrete slab

5. Earthquake and weather proofing

Virtually all long-term problems in relationships, organizations, and nations-at-large are either fundamentally caused, or egregiously exacerbated, by dishonesty, arrogant pride, disrespect, un-repentance, and selfishness. Honesty, humility, reverence, rectification, and service are antidotes to these poisonous character flaws, which lurk nearly everywhere in our postmodern world. While they are not the only solutions to the deep, penetrating, and complex array of problems we face, they nevertheless form the foundation of all real solutions. Any lasting success of any kind always begins and ends with character and integrity to true principles and universal laws. Just as foundation piles must be driven deep into the Earth's surface in order to reach bedrock, our own life decisions must be rooted firmly and deeply in veracity, reality, respect, self-improvement, and productive contribution.

One of the most famous vertical structures in the Western Hemisphere is the Temple belonging to The Church of Jesus Christ of Latter-Day Saints in Salt Lake City, Utah. Temple Square-as the site is known - has been visited by over 100 million people since its dedication in 1892. Built from solid granite hewn from neighboring mountains, construction on the Salt Lake Temple began in 1852 and required 40 years to complete. Among the reasons for its protracted period of construction was persecution of the Latter-Day Saints by the Buchanan Administration during the so-called "Utah War" prior to the outbreak of the American Civil War, as well as the difficulty of hauling stone from mountain quarries to the valley construction site prior to the completion of the Transcontinental Railroad in 1866. Perhaps a lesser-known reason for delay, however, was the discovery in 1862 (ten years after ground had already been broken) that large sections of the temple's foundation had developed cracks due to the use of sandstone and too much mortar when they were being placed. It was a bitter discovery to those who had worked so hard and sacrificed so much in the preceding decade to get the massive foundation laid, but the fact remained that a faulty foundation would never support the weight of a granite temple. Brigham Young, the Church's President at the time, made the difficult decision to tear up the entire foundation and then re-cut and re-lay every stone to ensure there were no cracks moving forward. Additionally, Young called for the new foundation to include 16-foot footings hewn out of solid granite-a much stronger stone, which was later used to construct the temple's exterior walls as well. By using granite instead of sandstone, they could cut the foundation stones to fit together firmly without the use of mortar. Today, 154 years later, and 124 years after the temple's dedication, the Salt Lake City LDS Temple-one of the most prominent structures in the Salt Lake Valley and the American West-stands as a testament to the importance of patience and circumspection in following correct principles of engineering and architecture in building the foundation of a large structure designed to pass the tests of time and nature (The Mountain of the Lord, 1993) (Temple Square Blog, 2015) (Newsroom, 2016).

When constructing a foundation, a proper site must be secured whereby the subterranean geology is conducive to supporting the superstructure to be built atop thereof. Once a proper site has been identified and chosen, pile drivers proceed to drive large, steel piles deep into the ground in order to reach bedrock. Depending on the size of the skyscraper and the geology involved in the building's location, these piles can be driven between 100-200 feet deep! After sufficient piles have been driven deep underground, they are reinforced with concrete. It is then typical to pour a thick, concrete matte slab atop an intricately constructed lattice-work of rebar and other steel materials. Complex infrastructural engineering work by plumbers, electricians, and others must also be completed in concert with the construction of the foundation. Someday it will all be covered up, 
and few people will ever think about-much less see-what lies below the building's surface. The fact remains, however, that the efficacy and longevity of the superstructure itself is ultimately reliant on the success of the initial foundation construction.

Laws of physics, architecture, engineering, and construction must be followed religiously in the construction of a physical structure if it is to be safe, serve its purpose, and pass the test of time; there is no other way. Engineers, architects, and builders cannot arbitrarily determine how they would like to calculate, design, and build; they must follow the laws of their respective disciplines. If they fail to do so, the results could be costly-and even dangerous or deadly.

The SAL model suggests that this self-evident reality, rooted in verifiable mathematics and science, carries a nomological, metaphysical equivalent. Ironically, however, this vitally important subject is only peripherally addressed - if it is addressed at all-in any formal way in the academe. Neglecting such an all-important metaphysical science in the direction of our lives is, as absurd as it may seem, akin to neglecting to properly survey, measure, design, anchor, and reinforce a structure before proceeding to build it. This laughable scenario in the construction industry is, in fact, the sophisticated status quo for those who view physical and metaphysical morality (in both the personal and professional realm) as relative and arbitrary rather than fixed and certain.

The introduction of the SAL model is an attempt to fill this gaping hole by providing a much needed burst of rain upon an academic environment that has grown profoundly and acerbically arid amidst an extended, postmodern drought of principle centered-leadership at both the individual and organizational level. In so doing, we have intentionally steered clear of any one theological, philosophical, ideological, or political dogma or doctrine. The SAL theory, model, and philosophy are general, non-partisan constructs. We therefore leave specific policy questions to the politicians, specific questions of legalities to the lawyers and judges, specific questions of ethics and morals to the philosophers, and specific "thou shalts" and the "thou shalt nots" to the pastors, pontiffs, and prophets. Our goal is not to start a new political party or religion by dictating specifics in every arena of life choice. Our seminal intention is merely to teach correct principles (generally speaking) and then encourage wise self-governance among individuals and organizations when it comes to the specific moral and practical decisions and dilemmas of work and life.

\section{Stage 3: Taking Action}

The singularly prominent word that appears in both action research and Self-Action Leadership is ACTION. Without action, even the best-laid plans and designs are rendered relatively meaningless. It is action that consummates, animates, vivifies, and ultimately realizes whatever blueprints of life or work that a self-action leader may have carefully drawn up in one's Self-Declaration of Independence and Self-Constitution.

Stage four of the SAL model contains five action-oriented step-habits.

1. Self-discipline

2. Self-action in public

3. Self-action in private

4. World-altering strategies

5. Self-rewards and natural rewards

These five SAL step-habits are direct analogues to five construction steps involved in building a skyscraper's superstructure. These five steps are:

1. Punctually showing up to the work site

2. Concrete, steel, wood, glass, brick, mortar, drywall, etc.

3. Plumbing, wiring, and insulation

4. Carpenting, painting, and interior decoration

5. Landscaping 
Emerson has said that, "Nothing great was ever achieved without enthusiasm." We echo his sentiment with relation to self-discipline. In countless cases, the fundamental ingredient in existential growth and high achievement is not raw intellect and natural talent, but focus, hard work, consistency, and persistence.

A key component of self-discipline, of course, is taking consistent and persistence ACTION in both public and private settings. Over a decade ago, a Hall of Fame NFL quarterback spoke to an audience of college students at a large, State university. An author of this paper was in that audience. The most memorable thing about the former quarterback's speech for this author-in fact the only thing this author remembers from the speech-was when the quarterback told the students that even if you become successful and famous, most of your time will still be spent away from the cameras, and often alone by yourself. His implication, of course, was that whatever action (preparation) or inaction (laziness) you exhibit in private becomes a great catalyst for the results you eventually earn in the public arena. As Covey (1989) often taught, the "Private Victory" (p. 63182) always precedes the "Public Victory (p. 183-284)."

Action-oriented aides to self-action leaders include world-altering strategies as well as selfand natural rewards. Both of these concepts are borrowed from Neck, Manz, \& Houghton's (2017) Comprehensive Self-Leadership Framework. World-altering strategies refer to visual aides and other sensory reminders of what an individual desires to become and the goals one seeks to accomplish as a self-action leader.

Self-rewards are privileges an individual grants oneself upon following through on a given task or goal. Such rewards can help bolster motivation to undertake tasks as well as facilitate the self-discipline required to see tasks through to completion.

Natural rewards are found in the spontaneous satisfaction, fulfillment, and enjoyment derived from engaging in tasks that suit one's interests and talents. Tasks that engender natural rewards are enjoyable to do in and of themselves. Wise self-action leaders are wise and strategic in crafting for themselves lives and careers with built in tasks and goals that produce as many natural rewards as possible.

\section{Stage 4: Observation, Analysis, \& Change}

It has been said that, "If at first you don't succeed, try, try, again!" This mantra troubles us because it fails to include the all-important step of identifying whether or not your plan of action is sound to begin with. After each action, wise self-action leaders will observe and analyze the results they are getting, and then make necessary changes based on their observations and analysis. For a self-action leader, the mantra is therefore altered thusly: "If at first you don't succeed, figure out why, revise your plan, change your approach, and then try again!"

The four step-habits in Stage Four of the SAL model are:

1. Self-renewal

2. Self-observation \& external feedback

3. Self-analysis

4. Self-alterations

These four SAL step-habits are direct analogues to four construction steps involved in maintaining and upgrading a skyscraper after the initial construction has ended. These four steps are:

1. Maintenance

2. Security

3. Inventory and change recommendations

4. Replacements, renovations, and upgrades 
Self-renewal is the essence of Covey's (1989) seventh and final habit, which is to, "Sharpen the Saw" (p. 287). Efficacious self-action leaders are not robots or automatons; they are human beings who require a productive work-life balance attainable only through the regular application of effective renewal strategies.

Step-habits two and three-self-observation and self-analysis-are borrowed from Neck, Manz, and Houghton's (2017) Comprehensive Self-Leadership Framework. These step-habits enable self-action leaders to identify where their cognitions and behaviors are incorrect, hurtful (to self or others), inadequate, or weak. These two steps are vital prerequisites to making self-alterations (trying again). Step-habit four-self-alterations-involves making changes before you "try again."

Because the SAL model stages are designed to be cyclical (or strategically perpetuating) in nature, there is no end to the process. How, when, where, and why a self-action leader chooses to engage a given step-habit is up to each self-action leader. The goal, however, is always the sameexistential growth and success for self, and positive and productive contributions of service to others.

At the beginning of this paper, we rhetorically queried as to "how often" individuals in an organization should be trained, mentored, and coached. The answer is simple: early, often, and always. The purpose of the SAL model is not to complete each step once and be done; nor is it to practice if for a set period of time and then quit. Its design is to create Self-Action Leadership oriented habits that become deeply ingrained in an individual's performance-and eventually into their habits and character. The SAL model is not designed as a mere process; its function is to engender a new way of life both personally and professionally that leads to greater achievement, job-satisfaction, life-fulfillment, happiness, and holistic success.

\section{Connections to Project Management Science}

Action research is not the only discipline that the SAL model parallels. It should be noted that the four stages of the SAL model also mirror four (4) of the "five Process Groups" in Project Management (PMI, p. 5), as follows:

\section{PM Process Group}

Initiating

Planning

Executing

Monitoring and Controlling

\section{$\underline{\text { SAL Model Stage }}$}

Planning \& Preparation

Developing an Integrity-Based Character

Taking Action

Observation, Analysis, \& Change

The key difference between project management process groups and SAL model stages is that project management science adds a fifth group: "Closing" (p. 5). While closing is a critical component of completing a project, a self-action leader is theoretically never complete (perfect) in one's Self-Action Leadership; there will always be room for further improvement, growth, and future achievement. Closing is therefore not always relevant to action research because of AR's cyclical nature. Furthermore, it is never relevant to the SAL model because the SAL process is never officially closed.

\section{Implications for Practice and Research}

In their multilevel review of self-leadership as an academic discipline, Stewart, Courtright, and Manz (2011) found that, "At the individual level, studies consistently show that increased selfleadership corresponds with better affective responses and improved work performance. Findings [however] are not as consistent at the team level" (p. 185). Given the manifold conceptual similarities of Self-Action Leadership and self-leadership, it is reasonable to assume these S-L findings would also apply (generally speaking) to SAL. Based on Stewart et al.'s findings, we suggest that a wealth of research opportunity remains to be done at the team level in order to 
further corroborate this inconsistency, or perhaps discover avenues of - and vehicles for-creating greater consistency between individual and team findings over time.

While the execution of S-L or SAL will always be simpler and more straightforward at the individual level (where complete autonomy exists) than at the team level (where autonomy levels vary from organization to organization), we endorse the use of SAL at the team level just as Manz and Sims, Jr. (2001) and others have endorsed S-L at the team level in an effort to promote the creation of self-led work teams, which we believe are destined to be the work-teams of the future. Moreover, we believe that as S-L and SAL become increasingly known, understood, and applied, that improved work performances at the team level will become more consistent. Indeed, we believe that Manz and Sims, Jr.'s brand of leadership known as "SuperLeadership" - defined as "leading others to lead themselves" (p. 23) will eventually play a vital, and perhaps even a pivotal role, in the future as organizations and nations seek to safely and successfully navigate complex domestic and foreign challenges of unprecedented scope and scale.

Aside from SAL's obvious connections to self-managed and self-directed or self-led work teams, the implications for future SAL practice and research are boundless. This is due in part because SAL is such a new concept; it is also due to the universality of its application and utility.

Perhaps the most obvious place for immediate practice and research is to begin proliferating SAL training for individuals, groups, and professional organizations of all kinds, which will subsequently provide opportunities for scholars and researchers to begin measuring the long-term impacts of such training in individual and organizational settings.

While the S-L field has been around for over three decades, we suggest that a mere tip of the proverbial research "iceburg" has been accessed in terms of the long-term potential for both studying, applying, and then researching S-L and SAL in the academe, in public and private job sectors, and in the lives and careers of individuals. In conjunction with the SAL theory introduced last year, we introduce the SAL model herein in hopes that it will serve as a starting point for a widespread cultural paradigm shift regarding the vital importance of the individual's competence in, and capacity to, self-lead morally, wisely, and productively. In so doing, we re-affirm the words of President Theodore Roosevelt: "The quality of the Individual Citizen is Supreme." (Roosevelt, 1910).

\section{Conclusion}

Gandhi famously remarked that if you want to change the world, then "YOU must be the change you wish to see in the world." Self-change, self-improvement, self-discipline, self-mastery, self-purification are hallmarks of the SAL philosophy, theory, and model; they form the building blocks of efficacious organizations.

SAL is about taking personal responsibility as a citizen-at the organizational, local, national, and global level. It involves identifying personal limitations, taking active steps to develop oneself personally and professionally, and striving to make one's immediate sphere of influence-and the world at large-a better place. It is about making honest connections and building a high-functioning, integrated network within a complex global context. It is about building upon the positive aspects of life and implementing strategies to address social challenges. In the administrative sciences, it is about effectively addressing major challenges surrounding attracting a labor force with plenty of competence and character-and then providing additional opportunities for professional development and existential growth. We argue that SAL can be used as a professional development model for shifting the way individuals see themselves and their various roles within an organization. We are confident that such a model will enrich individual personal and professional development and contribute to the mission and vision of organizations everywhere.

Administrators everywhere can benefit not only from providing SAL instruction to their subordinates, but just as importantly, in embracing SAL themselves. Again, in the words of Clawson (2008): 
"I remember when Manz (1983) first came out with his work on self-leadership. At the time it seemed odd to me. I will admit I am a slow learner on some things. I have come to believe that one of the biggest leadership issues is the inability of people - even and especially managers and executives - to lead themselves [effectively]" (p. 175).

The time has come for leaders, managers, and workers alike to resurrect them in the academe and contemporary workplace for the benefit of themselves and their colleagues and subordinates (or superiors). We are confident that learning, applying, and making habitual Self-Action Leadership principles and practices will prove fundamentally antidotal to the deepest, long-term problems we currently face in the administrative sciences-and beyond. We invite administrators, educators, managers, leaders, and workers everywhere to embrace this new construct full of old principles of personal conduct and character development in support of an educational and corporate renaissance of personal and corporate character, integrity, and competence in support of increased individual and organizational productivity, profitability, viability, sustainability, and long-term success.

\section{References}

Albors-Garrigos, J., de Miguel Molina, B., and de Miguel Molina, M. Positioning in the Global Value Chain as a Sustainable Strategy: A Case Study in a Mature Industry. Journal of Administrative Sciences. 4(2). P. 155172.

Alves, J. C., Lovelace, K. J., Manz, C. C., Matsypura, D., Toyasaki, F., \& Ke, K. G. (2006). $\quad$ A $\quad$ cross-cultural $\begin{array}{lll}\text { perspective of self-leadership. Journal of Managerial } \quad \text { Psychology, } & \text { 338-359. }\end{array}$ doi:10.1108/02683940610663123

Anderson, L. (2006). Analytic autoethnography. Journal of Contemporary Ethnography, 375(4), 395. doi:10.1177/0891241605280449

Beaulieu, R.B. (2013). Action research: Trends and variations. Canadian Journal of Action Research. 14 (3). Pages 29-39.

Burchell, J., \& Cook, J. (2006). Confronting the "corporate citizen" Shaping the discourse of corporate social responsibility. International Journal of Sociology and Social Policy, 26(3/4), 121-137.

Carroll, A. B. (1998). The four faces of corporate citizenship. Business and society review, 100(1), 1-7.

Carroll, A. B. (1991). The pyramid of corporate social responsibility: Toward the moral management of organizational stakeholders. Business horizons,34(4), 39-48.

Chaucer, J. (1387-1400). The Canterbury Tales. URL:http://www.fordham.edu.halsall/source/CT- prologpara.html

Clawson, J. G. S. (2008). Leadership as managing energy. International Journal of Organizational Analysis, 16(3), 174-181. doi:10.1108/19348830810937943

Covey, S.R. (2004). The $8^{\text {th }}$ Habit: From Effectiveness to Greatness. New York, NY: Free Press

Covey, S. R. (1989). The 7 habits of highly effective people: Powerful lessons in personal change. New York, NY: Fireside.

Cunningham, B. M. (2008). Using action research to improve learning and the classroom learning environment. Issues in Accounting Education, 23(1), 1- 30. Retrieved from http://search.proquest.com/docview/210915234?accountid=10868 
Denzin, N. K., \& Lincoln, Y. S. (Eds.). (2011). The SAGE handbook of qualitative $\quad$ Research $\quad$ (4th ed.). Los Angeles, CA: SAGE.

DiLiello, T. C., \& Houghton, J. D. (2006). Maximizing organizational leadership capacity for the future: Toward a model of self-leadership, innovation and creativity. Journal of Managerial Psychology, 21(4), 319-337. doi:10.1108/02683940610663114

Doane, G. W. (1920). Life sculpture. In R. J. Cook (Ed.), One-hundred and one famous poems: With a prose supplement (Google Books version). Chicago, IL: Cable.

French, S. (2009). Action research for practising managers. Journal of Management Development, 28(3), 187-204. doi:10.1108/02621710910939596

Furtner, M. R., Rauthmann, J. F., \& Sachse, P. (2011). The self-loving self-leader: An examination of the relationship between self-leadership and the dark triad. Social Behavior and Personality, 39(3), 369-379. doi:10.2224/sbp.2011.39.3.369

Georgianna, S. (2007). Self-Leadership: A cross-cultural perspective. Journal of Managerial Psychology, 22(6), 569-589. doi:10.1108/02683940710778440

Gioia, D. (2002). Can poetry matter: Essays on poetry and American culture. St. Paul, MN: Graywolf Press

Gioia, D. (2004). Disappearing ink: Poetry at the end of print culture. St. Paul, MN: Graywolf Press

Houghton, J. D., \& Yoho, S. K. (2005). Toward a contingency model of leadership and psychological empowerment: When should self-leadership be encouraged? Journal of Leadership E Organizational Studies, 11(4), 65-83.

Houghton, J. D., \& Neck, C. P. (2002). The revised Self-Leadership Questionnaire: $\quad$ Testing a hierarchical factor structure for self-leadership. Journal of Managerial $\quad$ Psychology, $672-691$. doi:10.1108/02683940210450484

Jenkin, T.A. (2013). Extending the 4I Organizational Learning Model: Information $\quad$ Sources, Foraging Processes and Tools. Journal of Administrative Sciences. 3(3), 96-109. doi:10.3390/admsci3030096

Kuhne, G. W., \& Quigley, B. A. (1997). Understanding and using action research in practice settings. In A. B. Quigley \& G. W. Kuhne (Eds.), Creating practical knowledge through action research: Posing problems, solving problems, and improving daily practice (Vol. 73, pp. 23-40). San Francisco, CA: Jossey-Bass.

Lin, S.K. (2013). (Book Review) Human Resource Management, 11th Edition International Student Version. By David A. DeCenzo, Stephen P. Robbins and Susan L. Verhulst, Wiley, 2013. Journal of Administrative Sciences. 3(1). P. 4-5. doi: 10.3390/admsci3010004

Longfellow, H. W. (1912). The poetical works of Longfellow. Oxford, UK: Oxford University Press.

MacPhee, M., Chang, L.-L., Havaei, F., \& Chou, W.-S. (2014). A Descriptive Account of $\quad$ an $\quad$ InterProfessional Collaborative Leadership Project. Journal of Administrative Sciences. 4(3). $\quad$ P. $\quad 373-399$. doi:10.3390/admsci4030373

Manz, C. C. (1983). Improving performance through self-leadership. National Productivity Review (pre-1986), 2(3), 288-297. Retrieved from http://search.proquest.com/docview/236427761?accountid=10868

Manz, C. C. (1986). Self-Leadership: Toward an expanded theory of self-influence processes in organizations. Academy of Management Review, 11(3), 585-600. doi: 10.5465/AMR.1986.4306232 
Manz, C.C. (1992b). Self-leading work teams: Moving beyond self-management myths. Human Relations. 45 : 1119-1140.

Manz, C. C., \& Sims, H. P., Jr. (1980). Self-management as a substitute for leadership: A social learning theory perspective. The Academy of Management Review, 5(3), 361-367. Retrieved from http://www.jstor.org/stable/257111

Manz, C. C., \& Sims, H.P., Jr. (2001). The new superleadership: Leading others to lead themselves. San Francisco, CA: Berrett-Koehler.

Manz, C. C., \& Sims, H.P., Jr. (1987). Leading workers to lead themselves: The external leadership of selfmanaging work teams. Administrative Science Quarterly, 32(1), 106-129. Retrieved from http://www.jstor.org/stable/2392745

McKay, J., \& Marshall, P. (2001). The dual imperatives of action research. Information Technology E People, 14(1), 46-59. Retrieved from http://search.proquest.com.cardinal.fielding.edu/docview/222356732?accountid= 10868

Millet, R.L. (2000). Foreword to Callister, T.R. (2002). The Infinite Atonement. Salt Lake $\quad$ City, UT: Deseret Book.

Mumford, E. (2001). Advice for an action researcher. Information Technology E People, $\quad$ 14(1),

$12-27$.

Retrieved from http://search.proquest.com.cardinal.fielding.edu/docview/222358142?accountid= 10868

Neck, C. P., \& Houghton, J. D. (2006). Two decades of self-leadership theory and research: Past developments, present trends, and future possibilities. Journal of Managerial Psychology, 270-295. doi:10.1108/02683940610663097

Neck, C.P., \& Manz, C.C. (2010). Mastering self-leadership: Empowering yourselffor personal excellence (5 (th $^{\text {ed.). }}$ Upper Saddle River, NJ: Prentice Hall.

Neck, C.P., Manz, C.C., \& Houghton, J.D. (2017). Self-Leadership: The Definitive Guide Tto Personal Excellence. Thousand Oaks, CA: SAGE

Newsroom (2016). Granite and Faith: The Story of the Salt Lake Temple. The Church of Jesus Christ of Latter-Day Saints. URL: http://www.mormonnewsroom.org/additional-resource/granite-and-faith-the-s tory-of-the-salt-lake-temple

Osula, B. \& Ng, E.C.W. (2014). Toward a Collaborative, Transformative Model of Non- $\quad$ Profit Leadership: Some Conceptual Building Blocks. Journal of Administrative $\quad$ Sciences. 4(2). 87-104. doi:10.3390/admsci4020087

Pattni, I., \& Soutar, G. N. (2009). The effectiveness of self-management training in two culturally different countries. Journal of Management Development, doi:10.1108/02621710910972733

Project Management Institute (PMI). (2013). A guide to the project management body of knowledge (PMBOK®), Fifth Edition. Newtown Square, PA: Project $\quad$ Management Institute (Global Standard)

Roosevelt, T. (1910). Citizenship in a Republic. Speech delivered at the Sorbonne; Paris $\quad$ France. 23 April 1910.

Roubiczek, P. (1964). Existentialism: For and against. Cambridge, UK: Cambridge University Press.

Saiia, D. H., \& Cyphert, D. (2003). The public discourse of the corporate citizen. Corporate

Reputation Review, 6(1), 47-57. 
Sardar, S., Lee, Y.H., \& Memon, M.S. (2016). A Sustainable Outsourcing Strategy Regarding Cost, Capacity Flexibility, and Risk in a Textile Supply Chain. Sustainability. 8(3). P. 234. doi:10.3390/su8030234

Schumacher, E. F. (1977). A guide for the perplexed. New York, NY: Perennial.

Stewart, G. L., Courtright, S. H., \& Manz, C. C. (2011). Self-Leadership: A multilevel review. Journal of Management, 37(1), 185-222. doi:10.1177/0149206310383911

Stokes, S. L. (1994). Moving toward self-direction. Information Systems Management,

11(1). P. 40-46.

Temple Square Blog (2015). Interesting Facts You Didn't Know About the Salt Lake Temple. 26 May 2. URL: http://www.templesquare.com/blog/interesting-facts-y you-didnt-know-about-the-salt-laketemple

The Mountain of the Lord (Video). (1993). The Church of Jesus Christ of Latter-Day Saints. Johnson, P.N. (Director). Gasdik, N.J. (Screenplay)

Thoreau, H.D. (2001). Walden and other writings. New York, NY: MetroBooks

(C) 2016 by the authors; licensee Preprints, Basel, Switzerland. This article is an open access article distributed under the terms and conditions of the Creative Commons by Attribution (CC-BY) license (http://creativecommons.org/licenses/by/4.0/). 